\title{
Investigatingthe Effect of Therapeutic Taping on Trunk Posture and Control in Cerebral Palsy Children with Spastic Diplegia
}

\author{
Author \\ Marwa M. Ibrahim ${ }^{1}$ \\ ${ }^{1}$ Department of Physical Therapy For Growth and Development Disorders in Children and Its Surgery, \\ Faculty of Physical Therapy, Cairo University, Cairo, Egypt.
}

\begin{abstract}
Background: Cerebral palsy (CP) is considered as the most common cause of postural problems and motor dysfunctions in neuro pediatrics.

Purpose: This study aimed to investigate the effect of kinesiotape (KT) application on the trunk posture and control in children with spastic diplegic CP that were enrolled into physical therapy program.

Methods: The study included 30 spastic diplegic children. Those with deformities that could disrupt the balance in sitting and standing were excluded. The patients were randomly divided into two equal groups. The control group received physical therapy programand study group received $K T$ in addition to the same physical therapy program for 12 weeks. KT was appliedwith repetition for consecutivethree days and then removed leaving the skin free for 24 hoursduring the period of treatment.For metric instrumentation system was used to evaluate posture parameters: trunk imbalance, pelvic tilt, pelvic torsion, surface rotation, and lateral deviation, in addition to Growth motor functional measure-88 (GMFM-88) to assess the sitting (B) and standing (D) control. Balance was evaluated using pediatric Berg balance scale (PBBS).

Results: The comparisons of the measurements of the two groups before and after the treatment showed that postural parameters, sitting control, standing control and balance were statistically significantly improved in both groups. Comparing the post treatment results, study group was more statistically significantly improved than the control group, in the previous parameters, except in pelvic torsion and surface rotation, there were no significant differences.

Conclusion: It is suggested to apply KT ontrunk muscles along with the physical therapy program to improve trunk posture and control in cerebral palsy children of spastic diplegic type which is more effective than physical therapy alone.

Keywords: Cerebral palsy, spastic diplegia, Kinesiotape, Posture, Trunk control.
\end{abstract}

\section{I-Introduction}

$\mathrm{CP}$ is a permanent neurodevelopmental disorder of the immature braindue to lesion in a single or multiple locations causing problems of posture and movement control ${ }^{[1]}$. Thislesion produces motor and sensory deficits leading to impaired ability to maintain normal posture because of the lack of muscle co-activation 
and the development of abnormal movement compensation ${ }^{[2]} . \mathrm{CP}$ is the most common cause of neuromuscular spinal deformities in children ${ }^{[3]}$.

One of the most common clinical types of cerebral palsy is spastic diplegia in which there is sensory motor impairment in the lower extremities more than in the upper ones as well as significant weakness in their trunk musculature ${ }^{[4]}$

Postural control is the ability to control the body position in space to achieve orientation and stability ${ }^{[5]}$. In children with $\mathrm{CP}$, the major postural dysfunction is the inability to coordinate the activation of postural muscles in the right sequence, especially during the performance of functional activities ${ }^{[6]}$. This impairment leads to important functional constraints. Spastic diplegic children have been recognized clinically with their poor trunkposture and control that noticeably interfere with activities of daily life ${ }^{[7]}$. These children could display rounded lower back in sitting and flexed trunk with kyphotic curvature of the spine with trunk asymmetry ${ }^{[8]}$. Their mobility or gait are also impaired, and they may develop contractures and deformity in their spine and extremities ${ }^{[9]}$.

The goals of treatment in spastic diplegia focus on the prevention of disability and to promote functional independence by minimizing the effects of impairments, maximizing the gross motor function,decreasing the deformities and enhancement of optimal posture and movement ${ }^{[10]}$.

KTmethod which was first described by Dr. Kenzo Kasein $1996^{[11]}$ as it can be used to increase sensorystimulation,strengthen the weakmuscles, inhibit spastic muscles, increase joint stability, increase functional motor skills, helpwith postural control and improve functional independence in pediatric rehabilitation clinics in addition tothe physiotherapy programs ${ }^{[12]}$.

$\mathrm{KT}$, according to its inventor ${ }^{[11]}$, is said to inhibit muscle tone if it is applied distally to proximally, whereas application in the opposite direction is used to facilitate a weak muscle.

Results of different research works concluded that improvement in motor control can be achieved through enhancement of postural alignment, facilitation of sensor motorsystem and modulation of muscle tone. The goal of this study is to determine if KT could improve trunk posture and control in CP children with spastic diplegia.

\section{II- Materials and Methods}

\section{1- Subjects:}

Thirty diplegic CP children who were referred to the Out-Patient Clinic of the Faculty of PhysicalTherapy, Cairo University, were included in this study. Children from both sexes were selectedaccording to the following criteria: their ages ranged from 7 to 10 years $(8.4 \pm 1.85$ years),they were free from any associated disorders, the degree of spasticity ranged from 1 to 1 +according to the Modified Ashworth scale ${ }^{[13]}$, they were able to follow instructions given to themin both testing and training sessions. All children were able to sit and stand independently even with abnormal posture.They were free from any structuraldeformities; however, children demonstrated variable degrees oftightness. Children were excluded for any of the theseconditions: if they were medically unstable as determined by history, or medical records, if they had epilepsy, visual or auditory problems, if they had structural scoliosis, if they had participated in any previous application for therapeutic taping to the trunk muscles, and if they demonstrated allergic reactions to the adhesive KT. 
Once the children met the previousinclusion criteria, all parents signed an informed consent to include their children in the study which had been approved by the Ethics Committee of Faculty of Physical Therapy, Cairo University, Egypt and in accordance with the code of ethics of the world medical association (Declaration of Helsinki) for experiments involving humans. Then, the children were engaged in a three-day skin check to ruleout rare toxic responses to adhesive KT before full inclusion in this study. All children were assigned randomly (coin toss) to one of two equal groups:

(1) Control groupwho received the physical therapy program only; or

(2) Study group who received KTin addition to the same physical therapy program

\section{2- Instrumentation}

A- For evaluation: all children participated in this study were evaluated before and after 3 months of treatment by the following tools:

1. Formetric instrumentation system (Aesculapmeditec GMBH, Holland): It issued to assess the geometry of the vertebral columnin humans. It isbased on non-contact 3-D scan and spatialreconstruction of the vertebral column derived by a specificmathematical model ${ }^{[14]}$.

2. GMFM-88: It is a functional scale used to standardize the self-initiated movements and to measure the changes in gross motor function over time in CP children. This particular scale is widely accepted and easy to administer in outpatient clinics ${ }^{[15]}$. The scale consists of 88 items for gross development measurement represented in five main domains (A) for lying and rolling, (B) for sitting, (C)for crawling and kneeling, (D) for standing, and (E) for walking, running and jumping.

3. Pediatric Berg balance scale (PBBS): This 14 items scale was developed similar to the Berg Balance Scale but organized and designed to assess a child's developing balance skills.It is a valid instrument and it is used for evaluating effectiveness of interventions and quantitative descriptions of function in clinical practice and research ${ }^{[16]}$. Equipment and materials needed for this scale were: ruler, two standard chairs (one with arm rests and one without) and of appropriate height to maintain hips and knees in $90^{\circ}$ flexion, footstool, stopwatch, and 15 feet walkway.

\section{B- For Treatment:}

Kinesio tape: The $5 \mathrm{~cm}$ tape (KinesioTex, Gold; Kinesio UK, Newcastle upon Tyne, UK) was used.

\section{III- Methods}

\section{A- For evaluation:}

1. For metric instrumentation system: The procedures were explained to each child before assessment. Each Child was positioned two meters distant from the measurement systemand in front of the black background screenwith a completely bared back and buttocks and fully extended arms. Finally, the image was captured and the data was analyzed and printed out for each one. The results were plotted as a graphic protocol. Each graphic protocol contains some anatomical parameters which were calculated from certain anatomical landmarks. The anatomical landmarks were: vertebra prominence, sacrum point, left dimple, right dimple, and midpoint between both dimples.Five main values were produced (1) trunk imbalance, (2) pelvic tilt, (3) pelvic torsion,(4) surface rotation and (5) lateral deviation ${ }^{[13]}$.

2. GMFM-88: Here, in this study, domains (B) and (D) for sitting and standing control respectively, were evaluated. Testing was done without shoes and children wore shorts and T-shirts.The children were scored as $0=$ unable to initiate task, $1=$ initiates the task, $2=$ partially completes the task, $3=$ completes the task. 
3. PBBS: This test was used to measure balance before and after treatment for both groups. The child was instructed to maintain his/her balance while attempting the following tasks: sitting to standing, standing to sitting, transfer, standing unsupported, transfer, sitting unsupported, standing with eye closed, standing with feet together, standing with one foot in front, standing on one foot, turning 360 degrees, turning to lock behind, retrieving objectfrom floor, placing alternate foot on stool, reaching forward with outstretched arm. The scale scoring ranged from 0-4 as " 0 " indicates the lowest levelof function and "4" the highest level of function and the best of three trials was calculated.

B- For treatment:KT was applied on the erector spinae muscles from spinal level S1 to spinal level of C7 in the way Dr. Kase recommended (from insertion to origin) [11]. KT of $5 \mathrm{~cm}$ width was used in the form of "fan technique" bilaterally applied to provide apredominantly sensory inhibition on the erector spinae muscles. The bandswereapplied for three days and then removed leaving the skin free for 24 hours, then KT was applied again. The children who participated in the study received physiotherapy program for one hour, three days a week, for 12 weeks. The physiotherapy program included exercises toimprove the sitting and standing position,exercises directed toincrease sitting and standing balanceand activities to improve the upper extremity function includingreaching,grasping andrelease.

\section{Statistical analysis:}

The mean \pm standard deviation (mean $\pm \mathrm{SD}$ ) were calculated for each variable (thoracic kyphosis angle, lumbar lordosis angle, and pelvic inclination angle, for both groups (A and B) before and after treatment. The pre and post treatment results within groups werecompared using paired t-test. The differences between groupswere carried out using independent t-test. The level of significance was set at $\mathrm{P}<0.05$.

\section{IV- Results}

\section{I- Physical characteristics of the children:}

Children of both groups were ranging in age from 7 to 10 years $(8.4 \pm 1.85$ years), their heights ranged from 123 to $138 \mathrm{~cm}(132.2 \pm 5.6 \mathrm{~cm})$, and their weights ranged from 28 to $32 \mathrm{~kg}(29.657 \pm 2.08)$. The preliminary data revealed no significant differences between the pretreatment values in both groups.

The collected data was statistically analyzed using paired t-test and independent t-test. As shown in table (1), the results revealed a significant improvement $(\mathrm{P}<0.05)$ in all the measuring variables including trunk imbalance,pelvic tilt, pelvic torsion, surface rotation and lateral deviation, in addition to GMFM (B) and (D) , and PBBSin both study and control groups, when comparing their pre and post treatment results (table 1).

Table (1) comparison between pre and post treatment mean values (mean \pm SD) for both study and control groups

\begin{tabular}{llllll}
\hline Variable & & \multicolumn{2}{l}{ Control group } & \multicolumn{2}{l}{ Study group } \\
\cline { 3 - 6 } & & Pre & Post & Pre & Post \\
\cline { 3 - 6 } Trunk imbalance $(\mathrm{mm})$ & mean \pm SD & $16.3 \pm 3.677$ & $13.6 \pm 2.261$ & $16.8 \pm 4.534$ & $9.8 \pm 3.75$ \\
& p-value & 0.02 & & 0.0001 & \\
Pelvic tilt $(\mathrm{mm})$ & mean \pm SD & $9.65 \pm 2.13$ & $7.61 \pm 2.01$ & $10.43 \pm 2.70$ & $5.98 \pm 1.251$ \\
& p-value & 0.01 & & 0.0001 & \\
Pelvic torsion $\left(^{\circ}\right)$ & mean \pm SD & $11.353 \pm 3.11$ & $8.98 \pm 2.91$ & $12.122 \pm 3.64$ & $8.918 \pm 2.32$ \\
& p-value & 0.03 & & 0.007 & \\
Surface rotation $\left({ }^{\circ}\right)$ & mean \pm SD & $6.7 \pm 2.397$ & $4.83 \pm 2.554$ & $6.5 \pm 2.391$ & $3.75 \pm 2.320$ \\
& p-value & 0.04 & & 0.003 & \\
Lateral deviation $(\mathrm{mm})$ & mean \pm SD & $10.53 \pm 4.316$ & $7.75 \pm 2.58$ & $9.93 \pm 4.508$ & $4.63 \pm 2.302$ \\
& p-value & 0.04 & & 0.0004 & \\
GMFM $(\mathrm{B})(\%)$ & mean \pm SD & $34.84 \pm 8.40$ & $42.48 \pm 9.21$ & $35.85 \pm 7.25$ & $49.9 \pm 2.11$ \\
\hline
\end{tabular}




\begin{tabular}{llllll} 
& p-value & 0.02 & & 0.0001 & \\
GMFM (D) (\%) & mean \pm SD & $28.73 \pm 5.76$ & $33.23 \pm 4.83$ & $27.11 \pm 1.45$ & $37.85 \pm 2.82$ \\
& p-value & 0.02 & & 0.0001 & \\
PBBS & mean \pm SD & $30 \pm 2.2$ & $32 \pm 2.78$ & $31 \pm 2.3$ & $37 \pm 2.85$ \\
& p-value & 0.03 & & 0.0001 & \\
\hline
\end{tabular}

SD: Standard deviation, P- value: Level of significance, GMFM (B): Growth motor function measure for sitting control, GMFM (D): Growth motor function measure for standing control, PBBS: pediatric Berg balance scale

When comparing the post treatment results of both groups (study and control), there was a more significant improvement $(\mathrm{P}<0.05)$ in the study group than in the control group table (2) in all parameters, except in pelvic torsion and surface rotation, there was no significant difference between both groups.

Table (2) comparison between the post treatment mean values (mean \pm SD) for both study and control groups

\begin{tabular}{llll}
\hline Variable & $\begin{array}{l}\text { Control group } \\
(\text { mean } \pm \text { SD) }\end{array}$ & $\begin{array}{l}\text { Study group } \\
(\text { mean } \pm \text { SD) }\end{array}$ & $\begin{array}{l}\text { P- } \\
\text { value }\end{array}$ \\
\cline { 2 - 4 } Trunk imbalance $(\mathrm{mm})$ & $13.6 \pm 2.261$ & $9.8 \pm 3.75$ & 0.002 \\
Pelvic tilt $(\mathrm{mm})$ & $7.61 \pm 2.01$ & $5.98 \pm 1.251$ & 0.01 \\
Pelvic torsion $\left({ }^{\circ}\right)$ & $8.98 \pm 2.91$ & $8.918 \pm 2.32$ & 0.9 \\
Surface rotation $\left({ }^{\circ}\right)$ & $4.83 \pm 2.554$ & $3.75 \pm 2.320$ & 0.2 \\
Lateral deviation $(\mathrm{mm})$ & $7.75 \pm 2.58$ & $4.63 \pm 2.302$ & 0.001 \\
GMFM (B) $(\%)$ & $42.48 \pm 9.21$ & $49.9 \pm 2.11$ & 0.005 \\
GMFM (D) $(\%)$ & $33.23 \pm 4.83$ & $37.85 \pm 2.82$ & 0.003 \\
PBBS & $32 \pm 2.78$ & $37 \pm 2.85$ & 0.0001 \\
\hline
\end{tabular}

SD: Standard deviation, P- value: Level of significance, GMFM (B): Growth motor function measure for sitting control, GMFM (D): Growth motor function measure for standing control, PBBS: pediatric Berg balance scale

\section{V- Discussion}

In fact, to maintain a good and stable posture is a challenge, because stability requires complex interactions between nervous system, motor system, and the sensory system. In children with $\mathrm{CP}$, these interactions are known to be affected, which may be a reason of postural control impairment and the inability to maintain stability ${ }^{[5]}$.

In children with spastic diplegia who develop postural disorderbecause of muscle imbalance and spinal deformities, providing a straight posture is important in terms ofpreventing spinal and lower extremitydeformities, and developing handfunction ${ }^{[17,18]}$.

As the application of KT becomes widely used, it is found that the number of research works investigating the effect of KT in the literature increases. There is no study in the literature investigating the use of KT application which is used in CP children with spastic diplegia. The currentwork is the first study conducted to investigate the effect of KTapplication on trunk posture and control in CP children with spastic diplegia.

The gainedresults of this study were positivewith significant improvement in all the measuring parameters related to trunk imbalance, pelvic tilt, pelvic torsion, surface rotation and lateral deviation, with consequent improvement in sitting and standing abilities and balance in both study and control groups in favor of the study group, except in pelvic torsion and surface rotation parameters, there was no significant difference between both groups. 
The positive results may be due to the effects of KT:(1) increasing proprioceptiveand tactile facilitation; (2) controlling trunk movement in thefrontal and sagittal planes; (3) restoring optimal musclelength to provide a foundation for normal firing and recruitmentpatterns; (4) orienting the muscle force along more normalvectors; (5) stabilizing hypermobile joints and reducerelative flexibility; (6) assisting with static and dynamic balance;and (7) optimizing gravitational forces about the columnof segments by improving body alignment $^{[19]}$.

Recently, through their electromyographic data, authors suggested that KT can decrease spasticity by means of enhancing sensory inputs which will stimulate thesupraspinal centersand thusenhancing the kinesthetic and joint position sense which have the key role in the development of a proper motor schemas ${ }^{[20]}$.

KT was also investigated for its effects on gross and fine motor capacity, and functional independencein activities of daily living on a number of childrenwith hemiplegic CP with significant improvements after 12 weeks of application ${ }^{[21]}$.

Some studies have revealed that KT is beneficial inimproving trunk flexion in patients with acute spinal cord injuriesand in treatment of pain due to osteoarthritis ${ }^{[22,23]}$.

In one study, itwas found that KT applied in association with other treatmentmethods was effective in improving muscle function and proprioceptiveawareness in hemiplegic patients, in decreasing pain, and in providingbody straightness ${ }^{[24]}$. Authors also concluded that KT application in addition to occupational therapy programswere beneficial to improve upper extremitycontrol and function in acutepediatric rehabilitation clinics ${ }^{[25]}$.

In a study applied to childrendiagnosed as hypotonic $\mathrm{CP}, \mathrm{KT}$ applied on the abdominalmuscles was reported to increase transition from supine position to sitting position ${ }^{[26]}$.

It has been observed in this study that KT application in additionto physiotherapy aiming to improve trunk posture and control by modulating the muscle tone, increasing proprioceptiveperception and to support weak muscles had a goodeffect on functional levels and sitting postures of children.Improvement of trunk posture and control in children with diplegic $\mathrm{CP}$ is an important factor providingindependence in activities of daily living.

\section{Conclusion}

It can be concluded that KT application was clinically beneficial to improve sitting posture and poor sitting balance in children with a diagnosis of spastic diplegic CP. This study is thought to be important in terms oflighting the way for future studies about KT application.

\section{Acknowledgment}

This work was supported in part by the Faculty of Physical Therapy, Cairo University. The critical comment offered on the initial draft of this manuscript by our colleagues at the department of Physical Therapy for the Growth and Developmental Disorder in Children and its Surgery and department of Basic Sciences are very much appreciated. 


\section{Declaration of interest:}

The author reports no conflict of interest. The author alone is responsible for the content and writing of this paper.

\section{Source of fund:}

All work of this study was conducted in the outpatient clinic at the Faculty of Physical Therapy, Cairo University, Egypt and not funded, in whole or in part.

\section{References}

1. Umphred D (2001): Cerebral palsy, Neurological Rehabilitation. 4th ed. 259, 767.

2. Smith JC, Allen AS and Pratt PN (1996): Occupational Therapy for Children. 3rd ed. Mosby; St. Louis, 150-152.

3. Campbell SK, VanderLinden DW and Palisano RJ (2006): Physical Therapy for Children. Saunders, 625-635.

4. Tong-Wai R, Webster R and Shevel M (2006): A clinical and etiologic profile of spastic diplegia. Pediatric Neurology. 34(3): 212-218.

5. Shumway-Cook A, Woollacott MH (2011). Motor control: Translating research into clinical practice. Baltimore: Lippincott/Williams and Wilkins, 253-255.

6. Graaf-Peters VB, Blauw-Hospers CH, Dirks T, Bakker H, Bos AF, Hadders-Algra M (2007). Development of postural control in typically developing children and in children with cerebral palsy: Possibilities for intervention? Neuroscience and Biobehavioral Reviews; 31:1191-1200.

7. Damiano DL and Abel MF(1998): Functional Outcomes of Strength Training in Spastic Cerebral Palsy. Arch Phys Med Rehabil., 79: 119-125.

8. Park E, Park C, Lee H, Cho Y(2001). The effect of electrical stimulation on the trunk control in young children with spastic diplegic cerebral palsy. J Korean Med Sci;16:347-50.

9. Wilsdon J (1996): Cerebral palsy. In: Turner A., Foster M., Johanson SE, and Steward AM: Occupational Therapy and Physical Dysfunction (principles, skills and practice), Churchill living stone, New York, 395-431.

10. Olney S, Wright M (2000). Cerebral palsy. In: Campbell SK, editor. Physical therapy for children. Philadelphia: W.B. Saunders; 496-500.

11. Kase K, Tatsuyuk H and Tomoki O (1996) Development of KinesioTM tape . KinesioTM Taping Perfect Manual. Kinesio Taping Association 6-10, 117-118.

12. Kase K, Martin P, Yasukawa A (2006). Kinesiotaping in pediatrics.Fundamentals and whole body taping. Kinesio Taping Association, Albuquerque, New Mexico, USA; 9-30.

13. Bohannon R, Smith M (1987). Interrater reliability of a modified Ashworth scale of muscle spasticity. PhysTher; 67:206-7.

14. Hierholzer E (2001). Formetricrastersterography 3-D back shape measurement and analysis, Formetric Manual.

15. Palisano RJ, Hanna SE, Rosenbaum PL, Russell DJ, Walter SD, Wood EP, et al (2000). Validation of a model of gross motor function for children with cerebral palsy. Phys Ther;80:974-85.

16. Rose FM, Joan GS, and Jean MA. Pediatric Balance Scale (2003): A Modified Version of the Berg Balance Scale for the School-Age Child with Mild to Moderate Motor Impairment. Ped.Phys.Ther; 15, 114-128.

17. Furderer S, Eysel P, Hopf C, Heine J (1999). Sagittal static imbalance in myelomeningocele patients: Improvement in sitting ability by partial and total gibbus resection. Eur Spine J; 8: 451-7 
18. Hoglund A, Norrlin S (2009). Influence of dual tasks on sitting postural sway in children and adolescents with myelomeningocele. Gait Posture; 30: 424-30.

19. Cusick B (1997). Lower extremity management for children with CNS dysfunction: Developmental and closed-chain biomechanics: casting, orthotic and taping implications. Course Materials, October; $18-24$.

20. Tamburella F, Scivoletto G, Molinari M (2014). Somatosensory inputs by application of Kinesio Taping: effects on spasticity, balance, and gait in chronic spinal cord injury. Front Hum Neurosci; 8: 367.

21. Kara OK, Uysal SA, Turker D, Karayazgan S, Gunel MK, Baltac G (2015). The effects of Kinesio Taping on body functions and activity in unilateral spastic cerebral palsy: a single-blind randomized controlled trial. Dev Med Child Neurol; 57: 81-88.

22. Gonzalez-Iglesias J, Fernandez-de-Las-Penas C, Cleland JA, Huijbregts P, Del Rosario GutierrezVega M (2009). Short-term effects of cervical kinesio taping on pain and cervical range of motion in patients with acute whiplash injury: a randomized clinical trial. J Orthop Sports PhysTher; 39: 51521.

23. Chen WC, Hong WH, Huang TF, Hsu HC (2007). Effects of kinesio taping on the timing and ratio of vastusmedialisobliquus and vastuslateralis muscle for person with patellofemoral pain. J Biomech XXI ISB Congress, 1-5 July 2007, Taiwan, Podium Sessions; 40: 318.

24. Jaraczewska E, Long C (2006). Kinesio taping in stroke: improving functional use of the upper extremity in hemiplegia. Top Stroke Rehabil; 13: 31-42.

25. Yasukawa A, Patel P, Sisung C (2006). Pilot study: Investigation the effects of Kinesio Taping in an acute pediatric rehabilitation setting. Am J OccupTher; 60: 104-10.

26. Motyka-Miller C (2008). Does Kinesio Taping of the abdominal muscles improve the supine-to-sit transition in children with hypotonia?, http://www.kinesiotaping.com/kinesiotaping- for-abdominalmuscles-to-improve-the-supine-to sit- transition-in-children.php. (Eriflim: 05.10.2009). 